\title{
A SYNESIS COMO FORMA DE COMPREENSÃO
}

\section{The synesis as a form of the comprehension}

Francisco das Chagas Amorim de Carvalho ${ }^{1}$

RESUMO: Gadamer, quando estuda o sentido da philia para os gregos, constata que o modo como concebiam a amizade conduzia a uma ética da solidariedade, diferente da que se tem praticado. $\mathrm{O}$ hermeneuta, com a função de ser intérprete e transitar entre mundos, que razões tem para alcançar a harmonia entre o reconhecimento e a estranhęa? Para Eugênio Trias, a própria condição humana o beneficia com uma razão fronteiriça, daí a pertinência da razão poética e diferentes lógicas. Hoje, quando se apela para a empatia, este valor não pode ser considerado outro dever, se os valores são sentidos, mais que intuição intelectual, a compreensão exige intuição afetiva. Esta arte da compreensão é apresentada com o termo synesis no diálogo Ion de Platão e na Etica Nicomáquea de Aristóteles, e tem origem nos pitagóricos, afirmam María Zambrano e Gadamer. Para a compreensão [synesis], mais que educação das ideias, é vital a educação dos sentidos.

Palavras-chave: Amizade. Ética da solidariedade. Synesis. Compreensão.

ABSTRACT: Gadamer, when studying the meaning of philia for the greeks, notes that the way in which they conceived of friendship led to an ethics of solidarity. different from what has been practiced. The hermeneutic, with the function of being an interpreter and moving between worlds, what reasons does he have to achieve harmony between recognition and strangeness? For Eugênio Trias, the human condition itself benefits him with a frontier reason, hence the pertinence of poetic reason and different logics. Today, when empathy is called, this value cannot be considered another duty, if the values are felt, more than intellectual intuition, the comprehension requires affective intuition. This art of comprehension is presented with the term synesis in Plato's Ion dialogue and in Aristotle's Nicomachean Ethics, and comes from the pythagoreans, say María Zambrano and Gadamer. For the comprehension [synesis], more than education of ideas, the education of the senses is vital.

Keywords: Friendship. Ethics of solidarity. Synesis. Comprehension.

1 Professor adjunto da Universidade Federal do Piauí, Mestre em Artes, DEA em Filosofia, Doutorado em Filosofia (UNED-Madrid, Universidad de Sevilla); endereço eletrônico: fcarvalho@ufpi.edu.br. 


\section{1 - Exórdio}

A hermeneia é uma arte, abrange a leitura, a interpretação, a comunicação que vai além da linguagem escrita. Hermes, conforme a mitologia grega, é o mensageiro entre o mundo divino e o mundo humano, é o protetor do comércio; seu símbolo consiste de uma vara em que duas víboras se equilibram. Este símbolo mostra sua relação também com a arte de curar. Entre os gregos antigos a palavra "herma" ('pedra fronteiriça') em português persiste como ermo: o lugar pouco

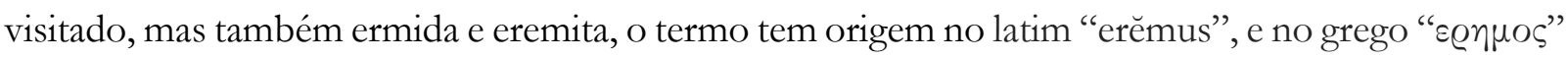
(érēmos). Sua figura assemelha-se a de Proteo, próprio da condição humana de metamorfosear-se. Hermes era figurado inicialmente com aspecto dionisíaco, personificava o espírito do encontro entre caminhos, nas encruzilhadas, nos limites. Eram seus signos os círculos, as alianças, os círculos que demarcam passagem entre-mundos. A ágora de Atenas tinha sua proteção.

Mircea Elíade (1955) vincula Hermes -deus romano Mercúrio- ao "deus ligador”, a ligação no mundo, o termo harmos leva a Hermes, que trouxe aos homens as artes e a amizade, os laços de amizade, a justiça e o pudor (o cuidado da conduta), é o deus que está para a ética como para a estética. Um intérprete que cruza as fronteiras com estranhos é um bermeneus.

O filósofo Eugenio Trias (1999) explica que a palavra limite tem origem no termo limes, que designava o lugar de cultivo e culto nos arredores das cidades romanas. Para Trias, considerando a condição humana: ser limítrofe entre o que aparece e o cerco hermético, é-lhe própria uma razão fronteiriça, uma lógica do limite. Hermes tinha presença nos lugares de travessias, onde houvesse encontro de direções ou cercos. Os seus atributos lhe conferem as virtudes do vento, transporta objetos, segredos, sementes e pensamentos, transita entre mundos.

\section{2 - Razão fronteiriça e diferentes lógicas}

Eugenio Trias em Lógica del límite, considera o homem um ser fronteiriço, que habita entre dimensões, escreve que o logos do limite é o símbolo, e que este é a palavra do ser, o acercamento à verdade do ser se dá através da poiesis, de modo estético. A este modo de pensar, María Zambrano, em Filosofía y poesía, define como razão poética, conforme se verifica a seguir com suas palavras: 
Senti que não eram "novos princípios" nem uma "Reforma da Razão" como Ortega havia postulado em seus últimos cursos, o que há de nos salvar, mas sim algo que seja razão, porém mais amplo, algo que se deslize também pelos interiores, como uma gota de azeite que apazígua e suaviza, uma gota de felicidade. Razão poética (...) é o que venho buscando. E ela não é como a outra, tem, há de ter muitas formas, será a mesma, em gêneros diferentes. (apud SANZ, 1993, p. 615).

Ortega y Gasset postulou uma razão vital, a razão poética de María Zambrano tem esse acréscimo da absorção, da experiência mística pessoal, que se mistura com nossa substancia. Não é o mesmo que a razaão estética de Chantal Maillard (1989), de experiência social. Ainda nesta relação entre razão, lógica e beleza, o filósofo Fredric Schiller propusera uma lógica da beleza. A potência da razão inclui ser vital, poética, estética, existe una lógica da beleza. A razãa simbólica, a lógica dos sentidos, tem já história em Vico, em Leibniz, em Cassirer, entre outros. Ela caracteriza o homem não por sua habilidade racional, sua mente é simbólica. A razão simbólica é conceito presente em diferentes áreas, das matemáticas às artes.

Chantal Maillard, em La razón estética, considerou a dimensão dos sentidos e subjetividades sem excluir a cognição, articulou mente e coração, percebeu que a consciência coletiva de nossas sociedades, no seu universo simbólico e experiências estéticas, produz categorias da sensibilidade, concluiu que uma educação da sensibilidade é indispensável à cidadania, a condição humana.

O que é difícil de pensar e de dizer, porque ainda não acontecido na história e no homem, resulta mistério à consciência, porém não deixa de ser a possibilidade que intui e imagina, mas esta imaginação, própria de uma razão poética, é de duplo aspecto, não só intui e capta o que está a caminho, mas ousa atuar, intervir, criar, [auto]construir-se enquanto constrói, essa outra face/rosto da razão, a que Maillard define razão estética, é um logos simbólico, em suas figurações, símbolos [enunciados poéticos, metáforas], mito porém é ação, movimento. Em que consiste esta razão? Não se trata de uma simples mudança de visão ou de interpretação, nem mudança de chaves ou de consigna, mas sim de atitude ante o mundo e a vida.

\section{3 - Sobre analogia e proporção}

Trataremos agora dos procedimentos da razão simbólica e dos fundamentos ou referências que serviram para María Zambrano elaborar o conceito de razão poética, ao tempo que nos aproximamos das fontes de onde teria brotado a sýnesis como forma de compreensão. 
Dizia-se que Pitágoras era filho de Apolo, ou de Hermes; assim como Orfeu, havia baixado aos infernos e ouvia as estrelas. Para os pitagóricos o mais sábio era o número, e o mais belo, a harmonia. Estudava-se a aritmética, a geometria e a música. O número constituía o acorde musical; buscava-se a harmonia mediante a música. Filolau, discípulo de Pitágoras, definia a harmonia como a unificação do múltiplo composto, a concordância [frag. B10]. Os pitagóricos aplicavam a analogia, a proporcionalidade, na aritmética, na geometria, na música, na estética, na ética, e na ontología; conheciam a arte das justas medidas para gerar harmonia, a matemática era para a música e também para a ciência. Uma lógica da escuta era cultivada para estimar, valorar, criar; a poética dos valores é necessária ao cultivo do ethos.

Os pitagóricos concebiam que o corpo recebia da alma a harmonia. A saúde era o resultado do equilíbrio (isonomia) e a mescla proporcionada (krasis) das qualidades (dynameis - energias), do calor com o frio. Daí a importância da respiração, do fluir, do movimento. Buscavam a harmonia dos contrários; concebiam a alma como acordo, era a harmonia do corpo. A alma realiza a proporção ou analogia, o corpo é amado pela alma, através dele ela pode ter sentidos. Permanece a lógica: alguém nos proporciona tal sensação, ou nos proporciona a sensação de acolhimento. Como estimar um afeto? Temos a impressão [ou intuição] de um evento ou ideia.

Os pitagóricos tiveram sua filosofia baseada na harmonia e proporção matemática, e esta consistia nesta analogia [ana - logia; pro - porção], os números, as proporções determinavam as coisas, estabeleciam os limites; a analogia ou proporção é limite; limites na cosmologia, que implica uma ordem [kosmos], cuja harmonia se refletia nas esferas, em tempos cíclicos, tempos vivos. O eterno retorno não como mera repetição, mas como análogo ou correspondência, a saúde resulta do estar bem proporcionado. Na ética, proporção e analogia significavam uma vida boa e constituíam as virtudes, e virtude era proporção [vis, virtus], a justa medida, o limite no uso das coisas, esta era a noção de analogia ou proporção para os pitagóricos, e deles passou a Platão e a Aristóteles. Na moral cultivada na tragédia a harmacia -a falha do herói- era não saber calcular bem suas ações.

Aristóteles, na Metafísica, acerca do saber propriamente humano escreveu: "por natureza o homem deseja saber"; mas com frequência ignora-se o "desejo”, o sentimento de querer necessário, uma atitude vital que conduz ao saber. Ainda: “por natureza”, é pois desde e a partir de sua própria natureza que se encaminha ao saber. Se não tateava no escuro, a esmo, que sentido era este que lhe encaminhava? Existe um sentido anterior e inerente a todo saber. Os pitagóricos buscavam atuar de acordo com a lógica da natureza. Ainda que seus dons tenham sido a música e a matemáticas, filhas do número, não da palavra, é certo afirmar que aquelas são anteriores ao logos, e este restrito à palavra? 
O número também é certo logos; número e medida é um gênero de razão. A música é medida, com ritmos, intervalos, intensidades, por isso, certo logos. Os pitagóricos cultivaram as artes do número, artes do tempo: o canto, a melodia, a música. A filósofa María Zambrano, em $O$ homem e o divino, escreveu sobre a reprovação de Aristóteles aos pitagóricos:

Espaço e tempo são categorias últimas do universo contemplado pelo homem. $\mathrm{E}$ ainda se poderia acrescentar que classificaram os mortais, divididos e escindidos, em duas categorias: os fascinados pelo espaço e os atraídos pelo tempo. Não é de estranhar, por tanto, que ao imaginar deuses ou ao pensar o divino, tenha sido feito guiado pelo espaço ou atraído pelo tempo. [tradução minha]. (2012, p.82).

A compreensão por analogia exige cuidar do espaço e do tempo; a compreensão tem a ver com tempo, com o espaço. E de tempo extrai-se eternidade. Se os pitagóricos chegaram a um deus, o tempo seria um dos seus aspectos. O tempo: a memória, a reminiscência, é um saber da alma. Dai o cuidado na purificação, o (caminhar) em reencarnações. Cronos devorava seus filhos; era o deus do silêncio e da música, racionalizada pelo número; era o pai dos números e da música. Cronos foi vencido por Orfeu, talvez por isto Pitágoras repetia as peripécias de Orfeu. Este venceu Cronos com o encanto mágico do número sagrado. Sobre o tema escreveu Zambrano:

E o canto e a lira -harmonia que é razão, mas também e sempre evocação- outra ação mágica, atraidora de almas e recordos. A música é a deusa que serve à memória. É coerente também neste ponto a lenda de Pitágoras que lhe atribui prodigiosa, sobre-humana, memória. A música nasceu para vencer o tempo e a morte, sua seguidora. O que se revela e se faz acessível pela música são os infernos do tempo da natureza, da alma entre a vida e a morte, que teve de atravessar para saber a si mesma e pôr-se a salvo (2012, p.84).

Atribuía-se a Pitágoras prodigiosa memória. A música e o canto nos seus compassos [ritmos] curavam o corpo e a alma. Pensar tem a ver com o espaço, mas também com o ritmo, com o tempo vivo. A tensão musical da lira é o sentido -o que se sente. A música é metáfora, foi metáfora da dialética nos pitagóricos e em Heráclito. Não se trata de um processo que assimile ou anule os contrários, uma síntese que salve a contradição, esta permanece em equilíbrio, onde os contrários estão presentes naquilo que são. A analogia busca o equilíbrio, integra o devenir [a teleologia] e a essência [ontologia] em uma visão que os estoicos definiram como prolepsis, onde predomina a relação e não só a substância; a analogia é o processo de aproximar-se à verdade, ao Outro, considerando similitudes, simetrias cósmicas, aparece a diferença, não somente a identidade. 
Zambrano escreve que os objetos da matemática e formas geométricas são os antepassados das "ideias", filhos da contemplação e não da palavra, quando ainda não havia “ideia” (2012, p.100); concebe a existência de diferentes lógicas, mas vincula estas lógicas a estágios. Será mero acaso que Sócrates, em Fedón (73d), ao falar de reminiscência utiliza a metáfora do amado e da lira? A música guarda íntima relação com a memória, a deusa mãe das musas é deusa dos recordos. Aos enamorados, a voz do amado ressoa como música, ressoa como se a conhecesse desde sempre. O ser do humano se constitui de memória, de tempo e de som em vibração: música, canto, Palavra, Verbo. Mas que relação existe entre o som e o espaço? A propósito, em $\grave{A}$ escuta, escreve Jean-Luc Nancy (2007, p. 40):

\begin{abstract}
Assim, haveríamos que compreender que a criança mesma -seu ser ou sua subjetividade-, que nasce com seu primeiro grito, é a expansão súbita de uma câmara de eco, uma nave onde ressoam ao mesmo tempo o que a expõe ao mundo e o que a chama [evoca], pondo em vibração uma coluna de ar, de carne, que ressoa em suas embocaduras: corpo e alma de um novo alguém, singular. Alguém que chega a si [da conta de si, desperta], ao escutar lhe dirigir a palavra, assim como ao se escutar gritar (responder ao outro? chamá-lo?) ou cantar, sempre e cada vez, em cada palavra, gritada ou cantada, exclamando como o fez ao vir ao mundo.
\end{abstract}

É mais, uma nota importante também de Jean-Luc Nancy (2008, p. 143), em As musas, mostra que etimologicamente o termo sentido indica caminho, a viagem e a ideia de encaminhar [tender a]. Encontra em Varrão a referência ao deus Sentinus, que encaminha a criança a este mundo, a sua percepção e seu pensamento, no momento de nascer. No dialogo Fedón, Sócrates comenta um sonho recorrente em que uma mulher vestida de branco aconselha-o a aprender música. A insistência desta metáfora sugere que nascemos como som, verbo feito carne, e haveremos de tornar-nos músicos, ou música. Somos palavra sonhada, dizem os índios guaranis.

Os pitagóricos não avançaram até a tragédia, porque nela todo conflito se resolve em determinado "instante" e tudo fica dito, preferiram permanecer "fiéis ao indizível”, não reduzir tudo em palavra, esta precipita o tempo, então, a experiência vivida modelaram através do número, em música, que não se esvai, mas se eleva (Zambrano, 2012, p.108). Os pitagóricos extraiam o essencial da vida, proporcionalmente, a harmonia. Aristóteles descreveu na Poética o canon para provocar a katharsis na tragédia, é dizer: calculou e modelou a trama.

O silêncio, o indizível, para os pitagóricos é carregado de sentido. Eles sabiam a arte das medidas, mas conheciam o imponderável, o imensurável: que não se mensura, nem se traduz em palavras. O caminho da alma ao tomar consciência de si, na senda órfico-pitagórica, aparece na 
metáfora da descida aos Infernos, onde o que acontece é indizível, e se resolve em música, nas palavras de Zambrano: "na forma mais musical da palavra: poesia" (2012, pp.108). A poesia de Rilke seria exemplo deste pensamento poético. O peculiar de Orfeu, próprio da alma grega, é que esta música sai das entranhas do inferno, não caiu do alto, sua origem, antes que celeste, é infernal, somente mais tarde aparecera a "harmonia das esferas", a harmonia vem depois do gemido e do encanto, esclarece Zambrano. É preciso ter um caos dentro de si para gerar uma estrela bailarina, escreveu Nietzsche. Este ethos será, de acordo com Zambrano:

(...) a ponte que a alma mediadora estende sempre entre a razão e a vida em seu padecer infernal; entre o sofrimento indizível e o logos (...) A música órfica é o gemido que se resolve em harmonia; o caminho da paixão indizível para integrarse na ordem do universo. Ordem e conexão das entranhas identificado com a ordem e conexão do universo pelos números, "a música é a aritmética inconsciente dos números da alma”, é a fórmula, a mais fielmente pitagórica, da essência da música, a chave do seu percurso; e que parece realizar-se na música de alguém contemporâneo que assim a definira (Zambrano 2012, p. 109).

A atitude proporcional e harmônica da analogia serviu aos pitagóricos para salvar a contradição, aproximar os opostos, reconciliá-los através de uma mediação e, conservar a ambos em tensão dinâmica. A analogia convida a compreender e viver na tensão das coisas, habitar e cultivar onde os limites se tocam e confluem, não necessariamente se justifiquem, porque a justeza, as medidas exatas, a conta acabada e sem restos, enquanto houver vida, inexiste.

\section{4 - A synesis como forma de compreensão}

No teatro -theátron: onde se faz teorias, e onde se vê em profundidade, os gregos praticavam atos de juízo como ato educativo, sua paideia. importava a eles imaginar como um acontecimento veio ser possível, dizer "o que são as coisas" caberia ao tempo. O coro, que traduzia a consciência coletiva, dirigia-se sem máscaras ao público na parábasis para comentar o acontecimento. Fixaram a máscara do terror, também do riso, para sentir como e pensar como, e nesta ação conhecer a si.

A phrónesis -ato de bem julgar, prudência ou sabedoria prática- vem complementada pela synesis. Na Ética Nicomáquea (libro VI), a synesis é a compreensão com a que seguimos a outro que fala dos seus sentidos e pensamentos acerca do que entende ser o melhor. O conteúdo e o modo de conhecer da synesis correspondem aos da phrónesis. Porém, na synesis o "entrar em acordo" uns 
com outros não se impõe nem dá ordens, pensa junto, o diálogo é compreensivo. A synesis como proporção é a virtude de saber estimar, fazer analogias; é arte das mesuras. Aprender proporção, carece de educação dos sentidos e da sensibilidade, é educação musical, aprender a medir e mediar. Seria frutífero aprender economia com a música.

A sinese [subst. feminino], é a construção sintática em que a concordância atende mais ao sentido do que ao rigor formal e na qual é permitido que um substantivo singular concorde com um verbo no plural e vice-versa. Nesta definição, mais que definição gramatical, é significativo que "a concordância atende mais ao sentido do que ao rigor formal", atitude ética e política: poder estar em uma situação com outro, por um sentido que é maior que as diferenças existentes.

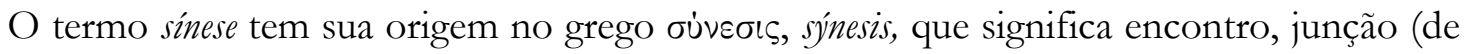
dois riachos), reunião de duas coisas em uma, correlatos: composição, conjunção; também compreensão, entendimento; do latim synĕsis,is é inteligência, entendimento, ou verbo ouví̇el que significa "aproximar pelo pensamento". A sýnesis está vinculada a sensatez, ao ser sensato, uma compreensão apoiada nos sentidos; uma sentença, mais que atender a uma lei, precisa fazer sentido.

Emilio Lledó, em Linguagem e história (1978), ressalta a conexão de filologia e filosofia, escuta e visão; explica que a filosofia em sua origem esteve vinculada ao termo synesis, que significa “compreender pelo ouvido", pensar é conversar, e era como Heráclito entendia a escuta do logos; tal termo significa o compreender e a compreensão; segundo o fragmento 22b: "O compreender é a suprema perfeição, e a suprema sabedoria é falar e obrar segundo a naturaleza, escutando sua voz". Compreender um texto ou alguém é escutar o que nos diz, tal como na escuta do logos, uma síntese nas cordas dos arcos para lançar uma flecha ou para extrair música e, assim, escuta-se uma "harmonia invisível que é melhor que a visível", o fluir do rio no jardim de letras, no espelho líquido da memória; se acercamos o ouvido, podemos escutar o rumor da eterna corrente. Assim como as letras (litera, litos) se convertem de silenciosas em voz viva e fluida, participando de uma harmonia invisível maior que a visível, também a natureza da escritura tende converter-se em uma "visão de escutas", em "ver sentidos"; talvez nossa meta e da Terra seja a transfiguração, assim anunciam Rilke, Hölderlin, Nietzsche e outros.

\section{5 - A synesis e a arte da interpretação}

No diálogo Ion, Sócrates ao encontrar com Ion, que chegara de Epidauro, das festas a Asclepio -deus da medicina- tece elogios aos rapsodos, aos grandes poetas, entre eles especialmente 
a Homero, que considera "o melhor e mais divino", em relação a este poeta, observa que é necessário “penetrar não só suas palavras, mas seu pensamento” (PLATÓN 1981, p.250).

Ion responde a Sócrates dizendo que nesta arte de bem interpretar, ouvir ou ser sensível e "penetrar o pensamento" de Homero, mostra-se melhor que outros rapsodos, pois ninguém "sabe dizer tantos e tão belos pensamentos sobre Homero" como ele, Ion; faz alusão a um modo de pensar belo. A nota 2 de edição comenta a distinção feita nesta passagem:

O dito -ta legómena- precisa de synesis, de percepção auditiva inteligente. O verbo synièmi (ouvinul), um dos que constituem o campo semântico do conhecimento, tem o sentido de captar algo pelo ouvido e seguir mentalmente essa percepção; um pensar constituído, pois, pela interpretação do dito; um primeiro broto hermenêutico que florescerá no Fedro. A terminologia de tudo o que diz Sócrates a Ion nesta passagem alude a esta dualidade entre o dito e seu sentido. (PLATÓN, 1981, p.250).

A arte de bem interpretar exige mais que a simples inteligência. Aristóteles, em Ética Nicomáquea, afirma que a Prudência "se orienta a dar ordens e seu fim último é o que deve fazer ou não"; mas a Inteligência se orienta a julgar, quando sejam correlatos: inteligência e boa inteligência, inteligente e bom entendedor, escreve:

a Inteligência não equivale a ter prudência nem a compreender. Assim como ao "aprender" se chama "compreender" quando se utiliza a ciência, assim sucede quando se utiliza a opinião para julgar assuntos que são próprios à Prudencia, quando é outro quem fala, e julgar corretamente ("bem" - eu - e "corretamente" -kalós- é o mesmo). Daqui o nome "Inteligencia" (synesis) -e, por este, o de "inteligentes"- a partir da que se manifesta em aprender: em efeito, ao "aprender" o chamamos com frequência "entender" (1985, p. 282).

Assim, o entendimento é certa inteligência. O "entender" a "outro que fala" exige uma escuta inteligente, uma escuta sensível; “julgar corretamente” implica um modo, Aristóteles associa este modo aos termos eu y kalós, ensýnesis: trata-se de uma compreensão articulada ao "bem”, sugere um engnómon (gnôme: razão, juízo) que é um "saber sentido”, belo e bom, um saber articulado a uma virtude; uma syngnóme, o mesmo que uma compreensão que não é distante ou indiferente, mas junto a (syn, daí sýnesis), entender como intendere: que tende a, e aqui cabe o intuir afetivo: sentido, que supõe a lógica de uma compreensão em movimento, que não está em fixar ou definir, trata-se de um saber que é uma aproximação, uma consonância cósmica, um saber por escutar. Aristóteles continua no parágrafo seguinte XI, onde escreve que a chamada "compreensão", é a própria do ethos 
"compreensivo", do "ter compreensão", é o "reto juízo do homem virtuoso". Este "ter compreensão" implica que se pode educar os sentidos para ela; não é o mesmo que educar para determinado valor, não se treina alguém para ter empatia. Portanto, enquanto a prudência é imperativa -dá ordens, instrui- a sýnesis é apreciativa. Escreve Aristóteles na Ética Nicomáquea (VI) ao tratar do Entendimento:

Existe ademais a synesis e a eusynesía, pelas quais chamamos a certos homens ou compreensivos e penetrantes. Não são estas qualidades o mesmo que a ciência em geral nem o mesmo que a opinião, pois se assim fosse, todos seriam compreensivos. Nem tampouco alguma das ciências em particular, como a medicina, que se refere à saúde ou a geometria às magnitudes. A synesis, em efeito não se refere às coisas eternas e imóveis, nem a todas as sujeitas a geração indistintamente, senão à aquelas sobre as que se pode estar perplexo e de deliberar. Se ocupa, pois, dos mesmos objetos que a prudência; porém, contudo, não são o mesmo synesis e phrónesis. A prudência é imperativa (epitaktikế), pois seu fim consiste em determinar o que deve ou não se fazer, enquanto que a synesis julga (kritiké); a synesis a tomamos aqui como sinônimo de penetração e o que dizemos dos compreensivos se entende também dos penetrantes (eusynetor)" (1985, p.281).

Este ver profundo, olhar penetrante, resulta mais de uma sensibilidade, ou de uma junção entre sentido e mente, mas não fruto de pura razão. O filósofo Héctor Zagal comenta que o sinético julga a ação de acordo com a lei, porém o ato sinético não é eminentemente ético -imperativo- não é um dever, assim atua o phrónimos. A compreensão sinética é de uma intuição sensível, considera Zagal:

Curiosamente, Aristóteles refiere también el término synesis a los animales21. Algunos animales superiores poseen cierta synesis. Esta laxitud del uso del término synesis sugiere un nexo muy fuerte con la sensibilidad. La synesis -la aprehensión sinética- involucra la sensibilidad. Echo de menos, nuevamente, mayores explicaciones (1999, p.137).

A synesis admite que na vida moral pode existir uma capacidade [potência] ou habilidade não discursiva; alguns indivíduos são capazes de "ver" -certa intuição-, sem mediação do discurso racional, a eticidade de uma ação; é "ver sentido", uma consonância cósmica na relação proporcional- de um singular dentro de uma ordem maior. Hector Zagal sugere que "a synesis é uma habilidade natural que permite escapar ao círculo vicioso da prudência” (1999, p.137). 


\section{6 - Por uma ética da amizade}

Gadamer recorre à tradição grega, a Platão e a Aristóteles, para evidenciar como a amizade não é um "conceito desconectado da trama da vida", mas que remete a uma experiência que configurou os modos de habitar o mundo de um povo que articulou suas práticas em torno ao sentido da philía que se traduz como solidariedade: o comum entre os homens. Escreve Gadamer: “Os gregos falaram de philía. Esse termo não alude ao que hoje chamamos 'amizade', mas à solidariedade, ao que entre os seres humanos vale como algo comum" (2002, p. 87).

No texto Amizade e solidariedade, Gadamer inicia com um trecho do diálogo Lisis, de Platão. Ressalta o primeiro pressuposto da concepção de amizade: a philía é como o estar em casa; o "caseiro", que em grego se designa sob a expressão oikeion: o próprio, o acostumado.

A diferença convida à analogia, ao diálogo, ao reconhecimento da opinião do outro; e ser vinculante significa ser para o outro uma morada, o oíkos grego, no qual se é capaz de acolher, este é o sentido de hospitalidade, escreve Gadamer:

Reconhecer-se no outro e que o outro se reconheça nele. Mas não só no sentido assim é esse, mas também no de conceder-nos reciprocamente o ser diferentes, mais ainda, por dizer em palavras de Droysen: Assim tens que ser, pois assim te quero. Isto é a verdadeira amizade. Aristóteles a chama amizade da areté” (2001, p. 81).

A phronesis, traduzida como prudência, deixa entender que na philía se põe em jogo um saber examinar, escolher entre múltiplas possibilidades, perguntar pelos motivos e consequências de nossas ações. Para Gadamer, seguindo a Aristóteles, a prudência não é uma forma "passiva de observação", é essencialmente atuar examinado, pretende compreender as paixões postas em jogo, atuar através do qual reconhecemos que o outro também busca a vida boa, isto exige a atitude coerente de uma razão prática, o saber examinar e bem julgar. Escreve Gadamer:

(...) a phronesis, não é uma distinção especial de quem filosofa. Mas ao contrário, aquele que reflexiona sobre o bom e o reto em general, se vê remitido a esse logos prático da mesma maneira que aquele que quer traduzir em feitos as ideias que ele tem acerca do que é bom e reto (2001, p. 128). 
A compreensão da philía implica não perder de vista o horizonte da synesis, que poderia ser entendida como saber aproximar-se. Não é suficiente a prudência, o saber examinar como medium edificante da ação. $\mathrm{Na}$ experiência da amizade se faz imperativa a synesis, o saber estar junto ao outro, saber que não vem nos processos de identificação. Ao contrário, acontece na escuta, no saber ouvir, ter a sutileza da arte de saber perguntar, e talvez responder. Portanto, a compreensão como encontro. As relações humanas são tão complexas, que para Aristóteles não é suficiente a prudência e acrescenta a virtude da synesis que não se resume na competência de julgar adequadamente determinada situação, mas saber aproximar-se a outra pessoa. Escreve Gadamer:

Temos que aprender a respeitar o Outro e ao Outro. Ou o que é o mesmo, temos que aprender a não ter a razão. Temos que aprender a perder no jogo (...) isto começa aos dois anos, ou talvez antes. Quem não o aprende cedo, nunca resolverá os problemas maiores da vida posterior (1990, p. 37).

Da fusão dos horizontes da phronesis e da synesis emerge um âmbito de compreensão sobre a amizade que a coloca na posição de um saber especial da razão prática. Para Gadamer, seguindo a Aristóteles, se na amizade põe-se em jogo a prudência e o saber estar junto aos outros, concluise que a amizade na sua dimensão ontológica é o exercício e a realização do reconhecimento do Outro, não por ser um semelhante, por identificação, no sentido de resumir o outro ao que somos, por isto mesmo, a amizade ou a empatia -a que agora se apela- não pode ser ensinada como uma tekhné, não é possível treinar a criança como deve vincular-se ao outro, não se trata de um dever; podese criar situações de vivência onde a criança cultive as disposições do seu ethos e de suas ações para em sua vida saber acercar-se aos outros, em jogo está a trama da vida compartilhada.

Nestas vivências podem compartilhar a mesma morada, os alimentos, cultivar espaços comuns, sem excluir as diferenças. Os horizontes pessoais e comuns se encontram em círculos de amizade, que se misturam e se transformam mutuamente. $\mathrm{O}$ outro não deve ser experienciado de modo reduzido: "esse tipo é assim", isto reduz o outro a uma apreensão, a compreensão do outro leva tempo, é preciso afeto: estar à disposição, sem exigir a unificação de perspectivas. É preciso educar para ser para o outro e com o outro. Colaborar para que o outro seja o que é, ou objetiva ser, para a afirmação do outro e sua realização. O outro se mostra como horizonte de compreensão; conhecer o outro como gesto de amor, não é indulgência, é modo de conhecer a si próprio. Cuidar de si por ser importante para o outro, é a filautia. 
Sobre amizade e estranhamento escreveu Gadamer: "os dois interlocutores desejam sinceramente entender-se. Sempre que se busca um entendimento, há boa vontade” (2002, p. 331). Entender (intendere) é tender a uma direção, não consiste em definir o que o outro é, mas em ser sensível ao aonde ele tende, e suas ações, ouvir seus sonhos, de onde nos chama; cogita-se uma perspectiva maior: que acte a perspectiva pessoal e a comum, que ambos a reconheçam e os envolva, desde a instância singular -manter-se vivo- até a instância macrocósmica -construção na Terra de uma morada comum. Nietzsche a definiu como amor fati, dizer sim, o que anima a vontade de viver.

O reconhecimento -este vem sempre acompanhado de certa alegria pelo acréscimo que o outro apresenta- está em perceber a amizade como âmbito do estranhamento, não mero encontro de "almas gêmeas": dois que se repetem, mas participam no horizonte da compreensão -no limite, limes- que é traduzido nos gestos de unidade: aliança, circular, abraçar; é multiplicação e não negação de diferenças. Neste horizonte da compreensão, entre a descontinuidade e o comum, instaura-se a mistura de horizontes, o âmbito do encontro, da pluralidade, neste lugar é possível olhar com menos prejuízos e ver/ouvir o que o outro quer nos fazer compreender quando nos insta: "Você me entende?", muitas vezes mesmo sem palavras.

\section{7 - A guisa de conclusão}

Não podemos nos colocar no lugar do outro, tal lugar não é apenas físico, nem metafórico, mas biológico, histórico, político. Mas vejamos bem: nossos ouvidos, nossos sentidos, foram feitos para o outro, nascemos dentro de outro, e passamos a vida buscando novamente acolhimento, nos braços de alguém, estendemos a mão, habitamos o coração de alguém. Podemos abrir horizontes se atendemos ao chamado do outro. A sýnesis é tomar consciência de si ao tempo que se coloca a disposição de outro, é uma inteligência sensível, especial, que abre um horizonte de compreensão; aprendemos a proporcionar acolhimento. Não é um ato de "bondade", é tecer a trama de sentidos, ampliar as dimensões do mundo e da vida.

A hermenêutica mais que um procedimento é uma atitude que busca entender a outro, como a disposição de um ouvinte ou leitor para entender um texto, ou o que se diz. A leitura de mundo, ou a hermenêutica de si e do outro, supõe ver a pessoa como um texto vivo. $\mathrm{Na}$ amizade constitui-se uma comunidade de sentido, os horizontes são ampliados para compreender como o outro elabora seu ponto de vista. Gadamer propõe pensar a philía não somente a partir dos vínculos, mas também a partir do estranhamento; estar à disposição do outro também pelo que dele não se traduz; talvez seja isto que nos encanta, que nos espanta e nos atrai, e nos resiste, por isto nos 
reconhecemos. É preciso questionar por que temos sido educados por espelhos, buscando o idêntico, isto força fixar tipos e caracteres, como se buscássemos a nós mesmos, talvez uma forma de reforçar o egoísmo e não a solidariedade.

Existe o limite, como limes, lugar de cultivo de uma ética da amiz̧ade [da solidariedade], a esta forma de compreensão, sua lógica ou logos atua através de uma escuta sensível, não é tanto saber ver, é mais aprender a ouvir; aqui não nos fará melhor o olhar frontal de predador; a disposição é para o encontro. As medidas ou mesura desta aproximação não vem com ter mais razão, não requer treinar para dar respostas, é mais tornar-nos o que somos, não é que não tenhamos sido, porém não fomos educados para a dimensão que em nós é para o outro, está em nós, mas é pública, foinos confiado cuidar para todos; tornar particular o que nos põe em contato com o mundo, o que é público: a língua, a palavra, as mãos para o carinho como para o trabalho, tem como motivo o controle das relações, dissipação da força da amizade, da empatia; e levar o que é do âmbito privado para controle público, pelo Estado, as intimidades, o que nos é íntimo, tem como motivo intimidar; diminuir, manter tímido, reduzir a potência de ser. Toda educação tem sido para termos poder e posse sobre nós, defender o que se pode chamar de "meu", que podemos carregar ou portar; mas defender aquilo que é de todos, as reservas ambientais, os rios, as florestas, a terra a cultivar é delegado a entes abstratos, alheios. Modo de compreensão como a sýnesis colabora para uma ética da amizade, uma ética da Terra.

\section{Referências bibliográficas}

ARISTÓTELES. Metafísica. Gredos, Madrid, 2013.

Poética. Editorial Gredos, Madrid, 2011.

.ética Nicomáquea. Gredos, Madrid, 1998.

ELIADE, M. E1 mito del eterno retorno. Ed. Alianza, Madrid, 1995.

Imágenes y símbolos. Taurus, Madrid, 1955.

GADAMER, H-G. Verdad y método II. Salamanca: Sígueme, 2002.

Verdad y método I. Salamanca: Sígueme, 2001.

. La herencia de Europa. Barcelona: Península, 1990.

. Mito y razón. Barcelona: Paidós, 1997.

Arte y verdad de la palabra. Barcelona: Paidós, 1998.

LLEDÓ, Emilio. Memoria de la ética. Taurus, Madrid, 1995.

Cadernos Cajuína, V. 5, N. 2, 2020, p. 73-87. 
La memoria del lógos. Taurus, Madrid, 1984.

. Lenguaje e historia, Ariel, Barcelona, 1978.

MAILLARD, Chantal. La sabiduría como estética. Akal, Madrid, 2008.

La razón estética. Laertes, Barcelona, 1998.

NANCY, Jean Luc. Corpus. Ed. Arena Libros, Madrid, 2003.

. A la escucha. Amorrortu, Buenos Aires, 2007.

. Las musas. Amorrortu. Buenos Aires, 2008.

PLATÓN. Fedón, Banquete, Fedro. tomo III, Gredos, Madrid, 1988.

Crátilo, v. II, Gredos, Madrid, 1987.

. Apología, Critón, Eutifrón, Ion, Lisis, Cármides, Hipias Menor, Hipias Mayor, Laques, Protágoras. Gredos, Madrid, 1981.

PORFIRIO. Vida de Plotino/Enéadas: libros I y II. Gredos, Madrid, 1992.

. Vida de Pitágoras. Argonaúticas Órficas. Himnos Órficos. Gredos, Madrid, 1987.

SANZ, J. M. La razón en la sombra. Siruela, Madrid, 1993.

SCHILLER, F. Sobre la gracia y la dignidad. Sobre poesía ingenua y sentimental. Una polémica Kant, Schiller, Goethe, Hegel. Icaria, Barcelona, 1985.

Kallias, Cartas sobre la educación estética del hombre. Anthropos, Barcelona, 1990.

Poesía filosófica. trad. Daniel Innerarity. : Ed. Hiperion, Madrid, 1994.

TRIAS, E. Lógica del límite, Barcelona, Destino, 1991.

La razón fionteriza, Barcelona, Destino, 1999.

ZAGAL A. Héctor. "Sýnesis, Euphyía y Anchínoia en Aristóteles. Algunas habilidades para el conocimiento del singular" en Anuario Filosófico, 63 (XXXII/1), 1999: pp. 129-145.

ZAMBRANO, María. El hombre y lo divino. F.C.E., México, 2012. 